\title{
Derivative Taxation Change: Impact for Asset Hedging in Germany
}

\author{
Ulrich R. Deinwallner"
}

PhD, Management and Finance, Walden University, 100 S Washington Ave Suite 900, Minneapolis, MN 55401, United States

DOI: $10.36348 /$ sjef.2021.v05i02.005

| Received: 08.02.2021 | Accepted: 22.02.2021 | Published: 23.02.2021

*Corresponding author: Dr. Ulrich R. Deinwallner

\section{Abstract}

Law makers have now decided a derivative taxation novelty in Germany. It was unclear how the new law impacted the profitability of investments in comparison of the former taxation (T1). The purpose of the study was to find an answer to the research question: How does the derivative taxation novelty (T2) in Germany impacts the profitability of derivative hedging strategy returns in the German financial market? For this study, a comparative, quasi-experimental research design was selected. ETF and warrant prices, a simple moving average (SMA), along with a beta hedging model, and a ttest were computed. The $\mathrm{T}(2)$ had an significant higher effect compared to $\mathrm{T}(1)$, with $4-17 \%$ and a $\mathrm{t}$-test with $\mathrm{t}(170)=$ $2.5042, \mathrm{p}<.000$. The $\mathrm{T}(2)$ unfolded its full potential with an investment amount of $€ 30 \mathrm{~K}$, while the share of $\mathrm{T}(2)$ was $2 \%$ per month of the investment amount when hedging with a $\operatorname{SMA}(50)$ and a warrant with a omega $=20 \omega$ (leverage) strategy. Conservative retail investors that followed a low risk short warrant strategy, needed to hedge large investment positions, had a frequent hedging requirement, which generated larger losses, were affected the most by $\mathrm{T}(2)$. I recommended to closer verify equality for sustainable investing. The study can be relevant for law-makers, financial advisors, banks, online brokers, retail traders, finance students to learn more about the effect of T(2) on their investments. Keywords: Derivative taxation Germany; beta hedging model; simple moving average strategy; performance analysis .

Copyright (C) 2021 The Author(s): This is an open-access article distributed under the terms of the Creative Commons Attribution 4.0 International License (CC BY-NC 4.0) which permits unrestricted use, distribution, and reproduction in any medium for non-commercial use provided the original author and source are credited.

\section{INTRODUCTION Derivatives}

Derivatives are a relevant instrument for the financial market, because companies require derivatives to manage their corporate risks. According to a "nonfinancial firms" study, from 1995 , at least $70 \%$ of the investigated companies use some form of financial engineering to respond to the changes of interest rate, foreign exchange, or commodity price risk [1]. Financial firms, such as banks, saving and loans, and insurers are all active in derivative markets in some form or the other. Even though the risk types that managers are confronted with, can vary across the industries and sectors, however, commonality exist in using derivatives as instruments to hedge risk to respond to the volatile movements of the financial markets [2]. In Germany, about 9.7 million people held stocks, investment funds or exchange traded funds (ETF) in 2019 [3], which is a share of about $12 \%$ of the Germanys. There are about 15 issuer banks in Germany that offer derivatives that cover about $90 \%$ of the issued warrants and investment products with a market volume of about $€ 60-€ 75$ billion in 2020 [4]. Therefore, derivates are an important element of the financial market to manage the corporate and the financial risk of investors.

The derivates that are traded at the financial markets are often over-the-counter (OTC) derivatives, and are private contracts that are determined by the changing price of some underlying financial asst or commodity [5]. To manage risk, the main derivatives that are commonly used in Germany and are relevant for taxation, are: (a) Futures, (b) options, (c) contract for difference (CFDs), and (d) warrants (HebelZertifikate, Optionsscheine and so forth). Depending on the account size, the financial knowledge, and the experience of the investor, various products with different complexity levels can be selected for professional, semi-professional, or retail investors.

Next to hedging corporate and financial risk, derivatives are also used as an instrument of speculation, where professional, semi-professional or retail investors follow various kinds of different investment strategies to leverage their profits with derivates. A commonly used investment strategy of the technical analysis, to gain excess returns, is to generate 
trading signals by using a simple moving average (SMA) strategy. For example, with a SMA strategy buy or sell signals can be obtained if the security price crosses the SMA price from below (i.e., buy / long / Bull phase) or crosses the SMA price form above (i.e., sell / short / Bear phase) [6].

Traditionally, the public does not approve of speculators, while law makers do not approve of shortterm profits and tend to favor long-term savings, where investors hold assets over several years. According to this, the taxation regulations seem to reward long-term investors, compared to those who sell their investments quickly. Especially, short-sellers are seen as speculators and are often limited in their speculations through regulation of antispeculation rules in statutes, common law, in ancient doctrines, and at state or federal levels [5]. Therefore, the public and law makers stand antagonistic to the short-term use of derivatives.

\section{Transaction cost and Taxation in Germany}

A very important issues for investing are the transaction costs which the investor has to take into account for his investments. The transaction costs can vary, depending if the investor selects a branch bank or an online broker to invest at. For example, the transaction costs, for buying stocks at a value of $€ 5,000$, are in comparison at a German public branch bank (Stadtsparkasse Munich) $€ 50$ plus technical fee per trade, while an online broker (i.e., "Smartbroker") charges $€ 4$ per trade [7]. For derivatives the transaction costs are charged through a slightly larger spread that the underlying security exhibits (i.e., 1 - 4 points or pips or $\$ 0.04$ - \$0.4 for stocks, currency, oil, gold CFDs and so forth) and require a margin (i.e., $5 \%$ - $20 \%$ for CFDs); similar logic for futures [8]. Essentially, depending on the investor's decision, for which bank, broker or product he decides for his investments, the costs can vary tremendously.

Taxation has a similar high relevance for investing because the taxation also impacts the investments of an investor significantly. Since 2009, Germany has for the taxation of security gains the so called "Abgeltungssteuer" (former "Kapitalertagssteuer"), which is in this study subsequently referred to as $\mathrm{T}(1)$. Investors have a tax free-limit of $€ 750$ and $€ 51$ advertising fee for a single person (i.e., different for married persons). The $\mathrm{T}(1)$ tax-rate is $25 \%$ plus $5.5 \%$ solidarity tax plus $8 \%$ church tax charge for any security profits. All losses and transaction costs can be offset in the same type of investment (assets-class) or same pre-tax income form [9]. The $T(1)$ is valid as soon as the $€ 801$ tax free-limit is exceeded on the trading account of the investors. For example, a profit of $€ 5001$ from an ETF investment means that $€ 801$ can be subtracted, as tax free-limit; resulting in $€ 4,200 * 25 \%=€ 1050$ and $* 5.5 \%=€ 57.75$ and $* 8 \%=€ 84$ which equals in total $€ 1,191.75$ tax.
In January 2021, a derivative taxation novelty came in the focus of the German public through the law makers. The law makers or in specific the "Bundesfinanzministerium" (BMF) have decided, in the end of 2019 through a tax release, that the loss offsetting of stocks and derivate should now be under different taxation restrictions. Now, losses through stocks and derivatives can only be offset for an amount of $-€ 20,000$, starting retrospective from 2020. This law novelty of the EStG (Einkommensteuergesetz / income law), which addresses (next to others) citizens with an income from stocks and derivatives, still needs to be approved by the "Bundestag" [10]. If the "Bundestag" would votes for a change of the $\$ 20 \mathrm{EStG}$, the question can be raised: What impact can this decision have on the profitability of hedging or trading returns? In this study, I will subsequently refer to this derivate taxation novelty from 2019 as $\mathrm{T}(2)$.

The general problem of this study is that law makers have suggested in 2019 changing the existing law for 2020/2021, to generate more tax income for the state and to perhaps reduce speculations with derivative securities [5]. The specific problem is that it is unclear how the $\mathrm{T}(2)$ impacts the profitability of investors or traders who need to hedge their assets, investment funds, or investment risks. Therefore, this study can be relevant for financial market parties, investors with currency risks or interest rate sensitive investments, banks, online brokers who need to advise their clients, financial advisors, professional or retail traders or students who learn how to invest, and need to understand the quantitative effect of $\mathrm{T}(2)$ for their investments. The study is significant because a quantitative, comparative simulation of the German taxation is performed to assess the impact of the taxation change in Germany, which can add further insight to the financial literature issues of: (a) financial derivatives, (b) hedging, and (c) taxation.

\section{Research Question}

This study is guided by one research question (R), R1: How does the taxation $\mathrm{T}(2)$ impact the profitability of derivative hedging strategy returns in the German financial market?

\section{Summary}

For this study, I collected DAX30 data from 2001 until 2020 (20 years), to compute the price of an $\mathrm{ETF}$ and the price of a short warrant for the analysis. I conducted six analyses subsequently, by first, analyzing the performance of a DAX30 ETF SMA strategy. Second, I assessed the performance for a DAX30 SMA short warrant hedging strategy, while controlling for conservative and speculative investors. Third, the general metrics of the investigated data were displayed, containing: (a) n Bull or Bear phases; (b) values $<>0$; (c) values =0; (d) 1day Bear phases; and (e) knockouts (KO's). Fourth, I analyzed the impact of T(1) and T(2) to answer the research question and to obtain the share 
impact of $\mathrm{T}(2)$. With a higher share of $4-17 \%$, the impact of $\mathrm{T}(2)$ compared to $\mathrm{T}(1)$ was significant with a t-test with $\mathrm{t}(170)=2.5042, \mathrm{p}<.000$. Fifth, I provided an answer to the question, at what investment level does $\mathrm{T}(2)$ unfold its true potential? I found that with a $€ 30 \mathrm{k}$ investment amount, the $\mathrm{T}(2)$ share increased by almost $1 \%$, with $2 \%$ per month of the investment amount for a $\operatorname{SMA}(50 / 20 \omega)$ short warrant hedging strategy, and unfolded its true impact. Sixth, I presented a diagram in which I tested the trading of a $\operatorname{SMA}(50 / 20 \omega)$ short warrant strategy, with and without occurring KO's, and for an investment amount of $€ 50 \mathrm{~K}$. The diagram reviled, displayed, and supported the assumption that conservative investors with large accounts, a high frequent demand for hedging, and larger occurring losses, are mostly affected by $\mathrm{T}(2)$. The study can contribute to the finical literature of taxation in Germany and to the issue of hedging strategies. Therefore, the study can be relevant for law-makers, financial advisors, banks, online brokers, and retail traders, or students who want to learn more about the effect of $\mathrm{T}(2)$ on their investments.

\section{DATA AND METHODOLOGY Data Collection}

For the analysis, I use dividend adjusted daily closing prices (daily data), from the DAX performance index (DAX 30; Symbol: ^ $\mathrm{GDAXI}$ ) for the time period of January 01, 2001 until December 31, 2020 (20 years). I collect the DAX30 data from the internet source Yahoo!Finance [11]. The computations are performed with Microsoft EXCEL.

I make the following limitations for the results of this study in regard of German securities and for the data of the DAX30. Size effects might not be present in the selected data, since the DAX30 only represents large cap stocks. Other hedging strategies and hedging models have been mentioned in the literature, besides a SMA strategy and a beta hedging model like selected in this study (see method section). The scope in this study is only focused on quasi-experimental and comparative test settings to answer the RQ1. The findings can be relevant for financial parties such as professional- or retail traders, banks, brokers, financial advisors, lawmakers who are interested to learn more about the effect of $\mathrm{T}(2)$ on their investments.

\section{METHODOLOGY}

Subsequently, the equations are presented that are relevant for the study.

Beta Hedging Model:

$$
\begin{aligned}
& \beta^{*}=\frac{\rho_{E i} * \sigma_{E} * \sigma_{i}}{\sigma_{i}^{2}}=\rho_{E i} \frac{\sigma_{E}}{\sigma_{i}} \\
& h=\beta^{*} \frac{\sigma_{E}^{2}}{\sigma_{i}^{2}}
\end{aligned}
$$

To obtain the investment amount IA, to invest in the warrant, an investment value of $\mathrm{V}_{\mathrm{i}}$ (i.e., $\$ 5,000$ ) is required for the equation:

$$
I A=-V_{i} \beta^{*} \frac{\sigma_{E}^{2}}{\sigma_{i}^{2}}
$$

Where $\beta=$ Beta, $\sigma^{2}=$ the variance, $\sigma=$ the standard deviation (STD), and $\rho_{E i}=$ the correlation coefficient between $\mathrm{E}$ the asset (i.e., DAX30 ETF) returns and $i$ the hedging asset (i.e., DAX30 short warrant) returns $[12,13]$.

The here introduced beta hedging model is based on the correlation of two assets. The correlation based beta hedging model has been selected because it outperformed in certain criteria's other hedging models, as shown in a similar prior conducted comparison in the financial literature [14].

\section{Transaction cost:}

$$
o=V *(2 * c)
$$

Where, $\mathrm{V}=$ investment amount, $\mathrm{c}=$ sales commission, $\mathrm{o}=$ is the total costs implied for one trade (i.e., buy and sell action).

Simple Moving Average (SMA):

$$
S M A=\frac{P_{p}+P_{p-1}+\ldots+P_{p-(n-1)}}{n}
$$

Where, $\mathrm{P}_{\mathrm{p}}=$ the price of the asset $\mathrm{p}$; and $\mathrm{n}=$ the number of days considered for the closing $[15,16$, 11]

ETF Price:

$$
p_{E T F i}=V+\left(\left(L N\left(p_{i t}\right)-L N\left(p_{i t-1}\right)\right) * 100\right) \ldots[4]
$$

Where, $p_{E T F i}=$ the price of the ETF of asset $\mathrm{i}$, and $p_{i t}=$ the price of underlying asset $\mathrm{i}$ at time $\mathrm{t}$ (i.e., here DAX30), $\mathrm{V}=$ the last value starting with (i.e, $€ 100)$.

The Equation 4 displays how the price of a DAX30 long ETF is computed. For example, if the initial values is $\mathrm{V}=€ 100$, the $\mathrm{DAX}$ is at 13,000 points and increases by 100 points, then $\mathrm{LN}(13100)$ $\mathrm{LN}(13000) * 100=+0.77 \%$. This means for the ETF price $\$ 100+0.77=€ 100.77$. Through this form of computation a path dependency occurs, which means that if the index increases and declines again, the ETF price might not be at a break-even level again [17].

\section{Warrant Price:}

$$
p_{w i}=\left(K O_{i}-\left(p_{i}+a\right) * b\right)
$$


Where, $p_{w i}=$ the short warrant (i.e., knockout certificate; Hebel-Zertifikat) price of asset i (i.e., here DAX30), $\mathrm{KO}_{\mathrm{i}}=$ knockout value of the underlying asset $\mathrm{i}, \mathrm{p}_{\mathrm{i}}=$ price of the underlying asset $\mathrm{i}, \mathrm{a}=$ agio or premium, $b=$ stock split rate. For example, 13,000 $(12,000+10) * 0.01=€ 9.9 \mathrm{DAX}$ short warrant price. While the leverage ratio (omega) is computes $=\mathrm{KO}_{i} *$ b / $\mathrm{p}_{\mathrm{wi}}$, with for example $13,000 * 0.01 / € 9.9=13.3$ omega $(\omega)$. Since the premium of the warrant is often only known by the issuer bank, I will not compute a premium for the warrant price in this study [18].

Mean Difference Significance Test (t-test):

$$
t=\frac{X_{1}-X_{2}}{\sqrt{\frac{\sigma_{1}}{n_{1}}+\frac{\sigma_{2}}{n_{2}}}}
$$

Where, $\mathrm{X}=$ the average return, $\sigma=$ the STD, and $\mathrm{n}=$ the number of cases [16].

\section{Research Design}

I assume for the study that a retail investor holds and DAX30 ETF in an online broker depot. The retail investor will hedge his DAX30 ETF investment position with a DAX30 short warrant according to a $\operatorname{SMA}(50)$ and a $\operatorname{SMA}(200)$ price crossover (of the DAX30 ETF price) strategy (see Equation 4 and 5). Where, the SMA(50) strategy represents a short-term hedging frequency and a $\operatorname{SMA}(200)$ represents a longterm hedging frequency. The investor will trade at an online broker with transaction costs of $€ 4$ per trade with an investment amount of $€ 10,000, € 100,000$ and $€ 1$ Million. I will control for two kinds of investors, by considering two different warrant leverage (omega) strategies with: (a) a "conservative investor" $=20 \omega$ warrant strategy and (b) a "speculative investor" $=40 \omega$ warrant strategy. The hedging model is a correlation based beta hedging model (see Equation 1) that considers two assets, an ETF and a warrant to determine the hedging amount in EUR.

Subsequently, I will conduct the following tests, quasi-experiments, and comparisons for the DAX30 data, for the time period January 1, 2001 until December 31, 2020. In regards of the tests, I will first, assess the returns and the STD's for an DAX $30 \mathrm{ETF}$ Buy and Hold (BH) strategy and a DAX30 ETF SMA Bull phases strategy obtained of an $\operatorname{SMA}(50)$ and SMA(200) price crossover strategy in Table-1.

Second, I will assess the returns and the STD's for a DAX30 SMA short warrant hedging strategy, with a SMA(50) and a $\operatorname{SMA(200)~to~determine~the~SMA~}$ Bear phases, while controlling for conservative $(20 \omega)$ and speculative $(40 \omega)$ investors with two different warrant omegas strategies. This means for the warrant strategy that each buy action, obtained through a SMA
Bear signals, will lead to a buy of a warrant with the same omega of $20 \omega$ or $40 \omega$. In Table-2, I will display the hedging model coefficients.

Third, I will assess and display the metrics that occurred for the analyzed data: (a) $\mathrm{n}$ Bull or Bear phases; (b) values <> 0; (c) values $=0$; (d) 1day Bear phases; and (e) KO's.

Fourth, I will assess the returns and the STD's for the SMA(50) and SMA(200) Bear phase strategy, while controlling for conservative $\left(\begin{array}{ll}20 & \omega\end{array}\right)$ and speculative $(40 \omega)$ investors, and controlling for $\mathrm{T}(1)$ and $\mathrm{T}(2)$, and differentiated the results for a $€ 10,000$, $€ 100,000$ and $€ 1$ million investment amount. This fourth test will allow me to determine the $\mathrm{T}(2)$ average share ratio of $(\mathrm{T} 1+\mathrm{T} 2)$. For this fourth test, the logic of $\mathrm{T}(1)$ is, if the investment profit is higher than the tax free-limit of $€ 801$ for a single person, then $25 \%$ tax is applied plus $13.5 \%$ tax of the $25 \%$ tax amount (see example in the literature review), however, all losses can be offset. The logic of $\mathrm{T}(2)$ is that $\mathrm{T}(1)$ is applied, however, investment losses can only be offset to a limit of $-€ 20 \mathrm{~K}$.

Fifth, since the hedging coefficients will lead to only a fraction of the ETF investment amount, because of the different variances and correlation coefficient, I will consider nine different investment amounts from $€ 5,000$ until $€ 1$ million to determine: (a) the number of cases that $\mathrm{y}<-20 \mathrm{~K}$ and (b) the share of $\mathrm{T}(2)$ per month of the investment amount. This analysis will show at which level the $\mathrm{T}(2)$ unfolds its true potential and impact.

Sixth, I will present a diagram in which a comparison is conducted between: (a) SMA, (b) SMA $\mathrm{T}(1)$; (c) SMA T(2) DAX30 short warrant hedging strategy and under the condition with and without KO's during the tested time period, for an investment amount of $€ 50 \mathrm{~K}$.

Since a $\operatorname{SMA}(50)$ and a $\operatorname{SMA}(200)$ price crossover strategy are compared, I expect for the ETF that a different amount of Bear phases will occur. In order to establish a comparison for the data, between different lengths of the SMA Bear phases, I will divide the total amounts by $\mathrm{n}$ phases for a downward projection, and I will consider a "phase vs. month" coefficient for the data in my analysis of (n phases / (20 years * 12 months))

\section{Threats to Internal Validity and External Validity}

The DAX 30 data was corrected by deleting 37 missing values (now 5,073 total cases), which can minor impacts the internal validity. Further, a downward projection was conducted of the total results (of 20 years) to the results per phase, and through a coefficient the results were transformed to the results per month. The downward projection can led to 
rounding errors in this study which impacts the internal validity.

Since other investments or asset classes might impact the performance of individual investors differently, the taxation might vary in a comparison of different asset classes, which impacts the external validity. As indicated, the transaction costs can vary depending by which bank or broker the investor chooses to invest, which leads to external validity issues for a comparison of results with different transaction costs. The computation of the warrants prices can deviate, since there is an element to the equation (i.e., agio / disagio or premium) that is decided and computed by the issuer bank and can hardly be replicated, which can lead to internal and external validity issues. The selected hedging strategy, through a SMA, is only one form of how to hedge, and the results do not represent all the different kinds of hedging strategies there are in practice which can impact the external validity.

The hedging positions were bought and were held from the start until the end of a SMA signal. For the data, larger losses with equal sizes were simulated, according to the trading frequency in forms of KO's, to display a stronger effect of $\mathrm{T}(2)$. In regard of external validity, less KOs might occur in reality and an investor might have exited an investment earlier if the possibility of a $\mathrm{KO}$ occurs for his investment position. This aspect, of a simulated $\mathrm{KO}$-variable and earlier executions of the hedge position if losses can be expected, might lead in practice to deviation for the taxation amount and for the investor behavior compared to the computed model in this study.

The taxation with T(1) and T(2) from 2009 and 2019, as described in the literature review section, are in the tests and computations applied for all time periods. The results represent a simulation and a hypothetical impact on the security returns to understand the effect of taxation. The taxation for all periods of the data has an effect on the external validity in regard of generalizations, since the findings do not represent the true taxation period for assets in Germany that only occurred from $2009 \mathrm{~T}(1)$ and now for 2020/21 $\mathrm{T}(2)$ (derivative taxation novelty). The application of the offsetting might be different or more various in praxis than here in this study performed (i.e., for the time period). In this study I make no claim for completeness, correctness or actuality of the content as it could be in other form possible, especially from a legal or law maker point of view.

Because private investors tend to lose capital in the financial markets, this study is for educational reasons, does not represent investment advice, and investors should conduct their own research before investing their capital [19].

\section{Empirical Findings \\ Analysis and Discussion}

For the analysis, the data of the DAX30 dividend adjusted closing prices were collected for the time period January 1, 2001 until December 31, 2020. The data displayed some missing values, perhaps because of holidays or none available data in 37 cases. The data was corrected by deleting the missing values, which resulted in 5,073 total data cases. The data correction has no significant impact with $0.72 \%$ missing cases. A formation period of 200 trading days was required for the $\operatorname{SMA}(200)$, which means that the measurement started from October 5, 2001. For the computation continuous returns were computed, which were transformed to discrete returns. The initial value of the ETF was $€ 110$, since the ETF turned negative during 11-13.03.2003 with an initial value of $€ 100$. In this study, I present monthly average results in percent for a comparison. For example, I computed a daily average return from daily data for the ETF BH strategy and raised the return to the power of 20.9 days to obtain average monthly returns for a comparison. I constructed 4 variable from the ETF data, containing the $\operatorname{SMA}(50)$ and $\operatorname{SMA}(200)$ short warrant returns according to a omega $(20 \omega)$ and $(40 \omega)$ warrant strategy.

For these four variables, I accumulated the returns per phase (i.e., Bear phase), assessed the total results, applied the testes, and finally downward projected the results through $\mathrm{n}$ phases, and according to a "phase verses month" coefficient (n phases / 240 months). For the analysis and the data, I wanted to integrate a variable of larger, equal-sized losses, depending on the hedging frequency, in order to obtain and display a larger taxation effect. The algorithm for this simulated variable was that if longer loss series during the SMA Bear phases occurred, then KO's were assumed for the DAX30 short warrant returns. The return data of the short warrant was first set to zero, and then the full investment amount was subtracted as a large loss (see amount and effect of KO's in Table 3 \& 4, and Figure-1).

Table-1

\begin{tabular}{|c|c|c|c|}
\hline \multicolumn{4}{|c|}{ DAX30 ETF \& SMA Strategy, During 2001-2020 } \\
\hline Long & $\overline{\mathrm{r}}$ & $\sigma$ & $\overline{\mathrm{r}} / \sigma$ \\
\hline ETF BH Strategy & 0.37 & 13.06 & 0.03 \\
\hline \multicolumn{4}{|l|}{ ETF Bull Phase } \\
\hline SMA(50) & 2.93 & 12.62 & 0.23 \\
\hline SMA(200) & 1.37 & 6.58 & 0.21 \\
\hline
\end{tabular}


From Table-1, I can find that a SMA price crossover strategy outperformed a simple DAX30 ETF BH strategy. More frequent investors, could have achieved the best risk and reward profile of $(\overline{\mathrm{r}} / \sigma=0.23)$ with a SMA(50) strategy.

Table-2

DAX30 Short Warrant \& SMA Strategy, During 2001-2020

\begin{tabular}{|c|c|c|c|}
\hline & \multicolumn{3}{|c|}{ conservative $(20 \omega)$} \\
\hline Warrant Bear Phase & $\overline{\mathrm{r}}$ & $\sigma$ & $\mathrm{HM}$ \\
\hline $\operatorname{SMA}(50)$ & 5.58 & 40.80 & 3.21 \\
\hline \multirow[t]{3}{*}{ SMA(200) } & 1.88 & 30.63 & 7.57 \\
\hline & \multicolumn{3}{|c|}{ speculative $(40 \omega)$} \\
\hline & $\overline{\mathrm{r}}$ & $\Sigma$ & $\mathrm{HM}$ \\
\hline $\operatorname{SMA}(50)$ & 7.74 & 62.37 & 0.90 \\
\hline SMA(200) & 3.68 & 45.70 & 2.28 \\
\hline
\end{tabular}

Note. All values are monthly average returns in $(\%)(1$ month $=20.9$ days $) . \overline{\mathrm{r}}=$ return, $\sigma=$ standard deviation. $\mathrm{HM}=$ hedging model ratio for a DAX30 short warrant hedging investment in percent (i.e. $€ 10,000$ ETF x 0. $0321 \mathrm{HM}=€ 321$ short warrant invest). $\omega=$ the omega of the warrant, which leads to a higher or lower initial warrant price and leverage. A Bear phase occurred, if an ETF price crosses a SMA price from above to below.

From Table-2, I can find that a simple SMA hedging strategy would be profitable for an investor, without KO's, transaction costs, or taxation. The table differentiates between conservative $(20 \omega)$ investors and speculative $(40 \omega)$ investors, were for each Bear phase (i.e., ETF prices crosses the SMA price from above to below) a DAX30 short warrant with either an omega of
(20 $\omega$ or $40 \omega)$ was selected and held until a Bull phase started. All strategies were profitable with positive returns; however, the risk was higher for speculative investors who traded with a higher frequency of about $(\sigma=15-22 \%$ higher STD) for the assets. In Table-2, I also provided the HM coefficients to hedge the DAX30 ETF with a DAX30 short warrant.

Table-3

\begin{tabular}{|l|l|l|l|l|l|}
\hline DAX30 ETF and Short Warrant Metrics, During 2001-2020 \\
\hline & n phases & values <> 0 & values $=0$ & $\begin{array}{l}1 \mathrm{D} \text { Bear } \\
\text { phases }\end{array}$ & KO's \\
\hline $\mathrm{W}(50 ; 20 \omega) \mathrm{BE}$ & 171 & 89 & 82 & 49 & 33 \\
\hline $\mathrm{W}(50 ; 40 \omega) \mathrm{BE}$ & 171 & 70 & 101 & 49 & 52 \\
\hline $\mathrm{W}(200 ; 20 \omega) \mathrm{BE}$ & 57 & 27 & 30 & 14 & 16 \\
\hline $\mathrm{W}(200 ; 40 \omega) \mathrm{BE}$ & 57 & 16 & 41 & 14 & 27 \\
\hline $\mathrm{ETF}(50) \mathrm{BU}$ & 170 & 129 & 41 & & \\
\hline $\mathrm{ETF}(200) \mathrm{BU}$ & 56 & 45 & 11 & & \\
\hline $\begin{array}{l}\text { Note. ETF }=\mathrm{Exchange} \text { Traded Fund, W = the warrant, } \omega=\text { the omega (leverage), BE = Bear phase, BU } \\
= \\
\text { Bull phase, D = day, } \mathrm{n}=\text { the total number of (i.e., Bull or Bear) phases, KO = knockout, where the } \\
\text { warrant expires and the investment amount is lost. All values are absolute numbers. }\end{array}$ \\
\hline
\end{tabular}

From Table-3, it was clear that if an investor hedges an ETF investment with a derivative, knock outs (KO's), meaning large losses where the warrant price turns negative or expires, can occur. Most of the KO's were generate data according to the trading frequency through an algorithm to obtain equally large losses. For the $\mathrm{KO}$ algorithm, longer negative return series were rated with $0 \%$ return (value $=0$ ). In case of a $\mathrm{KO}$, the investor loses the complete investment amount of his hedging position. The lost investment amounts through the KO's were later subtracted from the DAX30 SMA short warrant strategy returns in the subsequent tests in Table-4.

However, the KO's reviled that for this data even a conservative investor, with a long-term strategy SMA(200), exhibited KO's in about $28 \%$ of the Bear phases during the tested time period. Further relevant to know is that only 1 day Bear phases can occur, which result in $0 \%$ return (value $=0$ ) and transactions costs are applied. This means, either a $\mathrm{KO}$ had to occur or a 1day Bear phase in order to obtain a $0 \%$ returns for an investor. Bear phases occurred 2.85 - 8.55 times per year, while a 1 day bear phase occurred with $25-29 \%$ of the phases for a frequent investor and a long-term investor.

For the analysis conducted in Table-4, I considered a hedging model that was computed according to Equation 1. In regard of the hedging model, a correlation of ( $\left.\rho_{E i}=-.977\right)$ was assumed and computed, where minor warrant price deviations (i.e., here rounding errors or in practice warrant price premium as displayed in Equation 5) were taken into account. 
Further in Table 4, two forms of taxation were applied: (a) $\mathrm{T}(1)$ and (b) $\mathrm{T}(2)$. The tax was computed for the end of each year. The tax free-limit was applied for $\mathrm{T}(1)$ and for $\mathrm{T}(2)$. Depending on the share of the taxation relevant positive returns, the tax was downwards projected form the total yearly tax to each positive return of all phases in the data set, since the tax is valid as soon as it exceeds the tax free-limit of ( $\mathrm{x}>$ $€ 801)$. Because for $T(2)$ it was only allowed to offset losses of maximum $-20 \mathrm{~K}$, the accumulated investment after tax profits of $\mathrm{T}(2)$ differed, compared to the after tax profits of $\mathrm{T}(1)$, which caused minor differences in the STD. The investment amount had a significant effect on the taxation and the monthly STD, meaning, the large the investment amount was, the smaller the STD became. A month per phase coefficient (n phases / 240 months) was applied to the taxation displayed in Table-4, while dividing the total tax amount by $\mathrm{n}$ phases and the hedging position to obtain return values.

I considered $€ 4$ for the transaction costs per trade in Table 4. The transaction costs were not a primary objective to this study, therefore an extra transaction cost versus results table was not provided. The transaction costs from the presented data in Tables
4 can be computed, by: c (i.e., 2 Buy and Sell *€4) / h (i.e., 0.0321 hedging coefficient) * V (i.e., $€ 10,000$ investment amount $))=2.49 \%$ per $\operatorname{SMA}(50 / 20 \omega)$ short warrant trade.

The returns of the DAX30 ETF BH strategy were not crucial for the results in Table-4, and were therefore as well omitted. In the assumptions prior to the tests (see research design), it was assumed that an investor buys and holds a DAX30 ETF over a time period of 20 years, for which no transaction costs or taxation is applied.

Finally and as described, larger equal losses, depending on the trading frequency, were simulated according to an algorithm (see research design or Table3 ), with KO's of about $20-30 \%$ for the $\operatorname{SMA}(50)$ and $30-50 \%$ for the $\operatorname{SMA}(200)$. For the $\operatorname{SMA}(200)$ the amount KO's was higher, because more longer Bear phases with longer loss series occurred. The KO simulation was relevant to answer the research question, and it was relevant because of the assumed relation: The larger the losses are, the stronger the T2 impact is assumed.

Table-4

\begin{tabular}{|c|c|c|c|c|c|c|c|c|}
\hline \multicolumn{9}{|c|}{ DAX 30 Short Warrant Costs \& Taxation, During 2001-2020 } \\
\hline & \multicolumn{4}{|c|}{ conservative $(20 \omega)$} & \multicolumn{4}{|c|}{ speculative $(40 \omega)$} \\
\hline Bear Phase Hedged & $\overline{\mathrm{r}}$ & $\sigma$ & $x>801$ & $\mathrm{~T}(1)$ & $\overline{\mathrm{r}}$ & $\sigma$ & $x>801$ & $\mathrm{~T}(1)$ \\
\hline \multicolumn{9}{|l|}{$\operatorname{SMA}(50 / \mathrm{T} 1)$} \\
\hline$€ 10,000$ & -9.47 & 54.66 & 5 & 0.00 & -17.94 & 76.53 & 0 & 0.00 \\
\hline$€ 100,000$ & -8.63 & 52.02 & 19 & 0.64 & -14.02 & 73.16 & 14 & 0.66 \\
\hline$€ 1,000,000$ & -8.59 & 51.87 & 28 & 0.75 & -13.78 & 72.22 & 18 & 0.93 \\
\hline \multicolumn{9}{|l|}{ SMA(200/T1) } \\
\hline$€ 10,000$ & -4.70 & 38.01 & 5 & 0.13 & -7.26 & 54.96 & 2 & 0.00 \\
\hline$€ 100,000$ & -4.68 & 36.51 & 7 & 0.32 & -7.06 & 50.85 & 5 & 0.46 \\
\hline \multirow[t]{3}{*}{$€ 1,000,000$} & -4.68 & 36.38 & 7 & 0.35 & -7.06 & 50.34 & 6 & 0.54 \\
\hline & \multicolumn{4}{|c|}{ conservative $(20 \omega)$} & \multicolumn{4}{|c|}{ speculative $(40 \omega)$} \\
\hline & $\overline{\mathrm{r}}$ & $\sigma$ & $\mathrm{y}<-20 \mathrm{~K}$ & $\mathrm{~T}(2)$ & $\overline{\mathrm{r}}$ & $\sigma$ & $\mathrm{y}<-20 \mathrm{~K}$ & $\mathrm{~T}(2)$ \\
\hline \multicolumn{9}{|l|}{$\mathrm{SMA}(50 / \mathrm{T} 2)$} \\
\hline$€ 10,000$ & -9.47 & 54.66 & 0 & 0.00 & -17.94 & 76.53 & 0 & 0.00 \\
\hline$€ 100,000$ & -8.63 & 52.02 & 0 & 0.64 & -14.02 & 73.25 & 0 & 0.66 \\
\hline$€ 1,000,000$ & -9.63 & 51.87 & 60 & 1.95 & -14.06 & 71.28 & 35 & 1.28 \\
\hline \multicolumn{9}{|l|}{$\operatorname{SMA}(200 / \mathrm{T} 2)$} \\
\hline$€ 10,000$ & -4.70 & 38.01 & 0 & 0.13 & -7.26 & 54.96 & 0 & 0.00 \\
\hline$€ 100,000$ & -4.68 & 36.88 & 5 & 0.32 & -7.06 & 51.31 & 0 & 0.46 \\
\hline$€ 1,000,000$ & -5.55 & 33.79 & 28 & 1.46 & -7.75 & 45.89 & 32 & 1.54 \\
\hline \multicolumn{5}{|c|}{$\mathrm{T} 2$ average share of $(\mathrm{T} 1+\mathrm{T} 2)$} & & & & 0.60 \\
\hline \multicolumn{9}{|c|}{$\begin{array}{l}\text { Note. All values are monthly average returns in }(\%) . \omega=\text { the omega (leverage). } \overline{\mathrm{r}}=\text { return, } \sigma=\text { standard deviation. A "month vs. } \\
\text { phase" coefficient was applied of }(\mathrm{n} \text { phases } / 240 \text { months). The table displays the investment amount of an ETF, meaning that } \\
\text { the hedging amount was smaller according to Table } 2 \text { (i.e., } € 10,000=€ 320.51) .(\mathrm{x}>801)=\text { absolute profits in } € \text { that are larger } \\
€ 801 \text {, column displaying number of cases. }(\mathrm{y}<-20 \mathrm{~K})=\text { absolute losses in } € \text { that are smaller than }-€ 20,000 \text {, column displaying } \\
\text { the number of cases. } \mathrm{T}(1) \text { or } \mathrm{T}(2)=\text { are the share in percent of } \mathrm{T}(1) \text { or } \mathrm{T}(2) \text { of the investing hedging amount per month. }\end{array}$} \\
\hline
\end{tabular}

From Table-4, I can find that a conservative investor with a frequent and large hedging investment amount, is taxed by $\mathrm{T}(2)$ the most with $0.86 \%$ on average per month of the investment amount, compared to a conservative long-term hedging investor with $0.64 \%$ on average per month. A speculative investors, who has a long-term hedging frequency, is taxed the most with $0.67 \%$ on average per month for $\mathrm{T}(2)$, compared to a speculative, frequent hedging investors with $0.65 \%$ on average. I can conclude that a conservative, frequent hedging investor is impacted the most by $\mathrm{T}(2)$, compared to all others. A reason for these results lies in the aspect that $(\mathrm{y}<-€ 20 \mathrm{~K})$ was mostly the case for the conservative, frequent hedging investor 
with 60 cases. However, the following variables were also influential for this result: (a) the n KO's, or the number of equal large losses (b) the hedging coefficients; (c) the STD, and (d) the $\mathrm{n}$ phases, or investment frequency.

The considered KO-variables and the taxation impacted the monthly average return data negative. Speculative investors lost about $-12 \%$ more capital of their investment, than conservative investors. The higher the investment amount was, the lower the deviation for the returns was. Bear phase profits that are relevant for taxation above a tax free-limit of $\mathrm{T}(1)$, were already for a small hedging amount of $€ 321$ the case, with 5 cases in 20 years (see Table $4 € 10 \mathrm{~K}, \operatorname{SMA}(50 /$
$20 \omega)$. Bear phase losses below $(\mathrm{y}<-€ 20 \mathrm{k})$ occurred in this dataset only for larger investment amounts, which means that retail trader with small accounts and high risk are less affected by the $\mathrm{T}(2)$, than retail trader with larger accounts, many transaction costs or large losses, and lower risk. In regard of the research question, it was interesting to see that the $\mathrm{T}(2)$ had a $10-17 \%$ higher impact compared to $\mathrm{T}(1)$, according to the average share of $\mathrm{T} 2$ in Table 4. Further, I determined the average share of T2 from the data of a $\operatorname{SMA}(50 / 20 \omega)$ with $50 \mathrm{~K}$ and without $\mathrm{KO}$ occurring, and found that the share equaled to a $4 \%$ higher impact. I can find that the $\mathrm{T}(2)$ has a $4-17 \%$ higher significant impact with a t-test with $\mathrm{t}(170)=2.5042, \mathrm{p}<.000$, compared to the former taxation method of $\mathrm{T}(1)$.

Table-5

\begin{tabular}{|l|l|l|}
\hline DAX30 Short Warrant Costs \& Taxation, During 2001-2020 \\
\hline SMA $(50 / 20 \omega)$ & $y<-20 \mathrm{~K}$ & $\mathrm{~T} 2$ \\
\hline$€ 5,000$ & 1 & 0.68 \\
\hline$€ 10,000$ & 20 & 0.83 \\
\hline$€ 15,000$ & 37 & 1.06 \\
\hline$€ 30,000$ & 59 & 1.88 \\
\hline$€ 50,000$ & 64 & 2.31 \\
\hline$€ 100,000$ & 68 & 2.67 \\
\hline$€ 250,000$ & 72 & 2.95 \\
\hline$€ 500,000$ & 72 & 3.04 \\
\hline$€ 1,000,000$ & 77 & 3.09 \\
\hline $\begin{array}{l}\text { Note. The investment amounts represent the values that were invested for a SMA(50) Bear phase } \\
\text { strategy, with an omega }=20 \omega \text { DAX30 short warrant. }(\mathrm{y}<-20 \mathrm{~K})=\text { absolute losses in } € \text { that are } \\
\text { smaller than - } € 20,000, \text { column displaying the number of cases. T(2) }=\text { is the share in percent of T }(2)\end{array}$ \\
of the investment amount per month
\end{tabular}

For Table-5, the question was: At what point does the $\mathrm{T}(2)$ starts to impact the investment amount significantly? The relation was assumed: The large the investment becomes, the more taxes needed to be paid, and the stronger the impact of $\mathrm{T}(2)$ can get. Therefore in Table 5, a SMA(50) Bear phase strategy for a DAX30 short warrant with a omega $=20 \omega$ strategy was investigated. The $\mathrm{T}(2)$ impacted the smallest investment amount of $€ 5,000$ directly, with one case in 20 years with a share of $\mathrm{T}(2)$ of $0.68 \%$ of the investment amount. At a $€ 30,000$ investment amount, the impact of the T(2) started to become most effective with an almost $1 \%$ increase to about $2 \%$ share of $\mathrm{T}(2)$ of the investment amount.

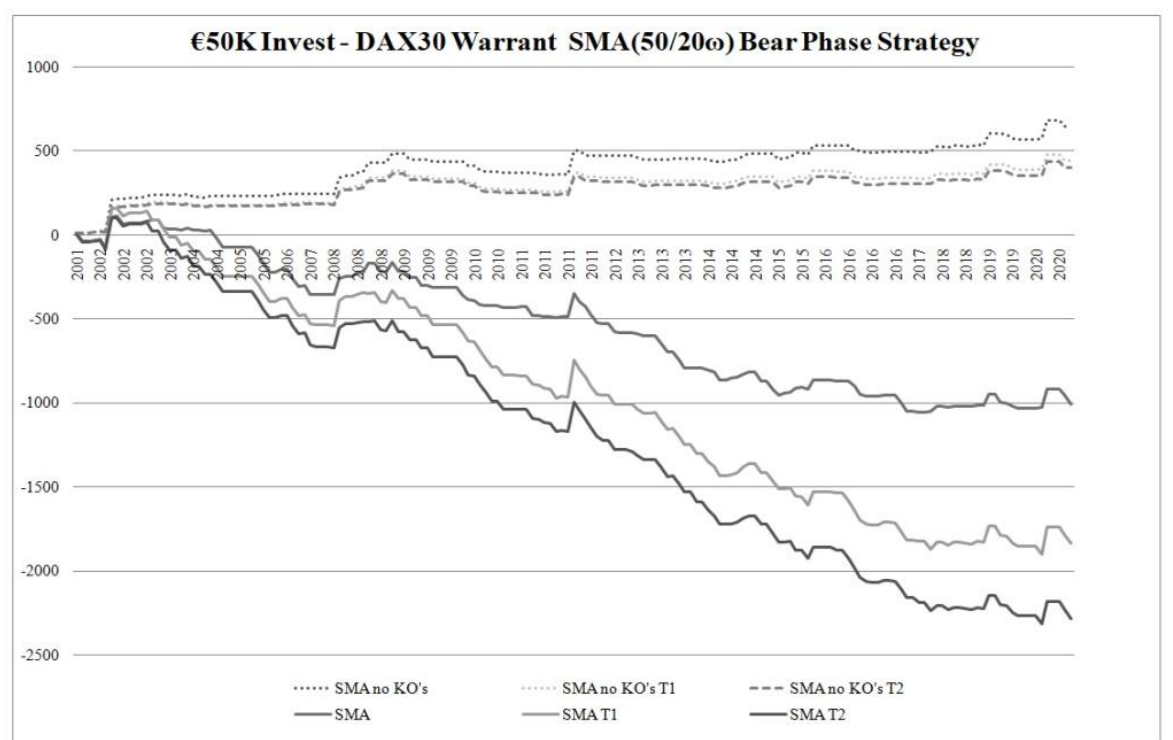

Fig-1: €50k investment amount invested in a DAX30 short warrant SMA(50/20 $\omega)$ Bear phase hedging strategy, with and without KO's during 2001-2020 
In Figure-1, a comparison was conducted between a SMA(50/20 $\omega)$ DAX30 short warrant Bear phase hedging strategy, with and without KO's and the taxation of $\mathrm{T}(1)$ and $\mathrm{T}(2)$ for an investment amount of $€ 50 \mathrm{~K}$. From Figure-1, I can find that the SMA hedging strategy was most profitable without KO's; however, the taxation impacted the returns almost equally. Though the application of the KO's, the SMA strategy returns started to decline, and the difference between $\mathrm{T}(1)$ and $\mathrm{T}(2)$ became most dominant. The large the losses become, the larger T(2) unfolds its impact, and the large the total losses become.

\section{CONCLUSION}

The research question of this study was: How does the taxation $\mathrm{T}(2)$ impact the profitability of derivative hedging strategy returns in the German financial market? I can find from the analyzed data that a speculative hedging retail investor, that choose a high risk and has a small investment accounts, is less affected by the $\mathrm{T}(2)$ than a conservative retail investor that chooses a low risk and has a larger investment accounts, a frequent hedging requirement that generates many transaction costs or large losses (see Table-4). The reason that a conservative investor exhibits a higher amount of losses of $(\mathrm{y}<-€ 20 \mathrm{k})$ in the dataset, which is relevant for the taxation of $\mathrm{T}(2)$, is, the results are influenced by the hedging model computed investment amount and therefore the variance of the data. This means that the following variables were influential for this result: (a) the n KO's, or the number of equal large losses (b) the hedging coefficients; (c) the STD, and (d) the $\mathrm{n}$ phases, or investment frequency. At a $€ 30,000$ investment amount, the impact of the $\mathrm{T}(2)$ starts to become most effective with about $2 \%$ share per month of $\mathrm{T}(2)$ of the investment amount in this dataset (see Table 5). Further, the larger the losses become and the larger the investment amount is, the larger T(2) unfolds its impact and the larger the total losses become (see Figure 1). $\mathrm{T}(2)$ has a $4-17 \%$ higher significant impact for the investor, compared to the former taxation method of $\mathrm{T}(1)$, with a $\mathrm{t}$-test with $\mathrm{t}(170)=2.5042, \mathrm{p}<$ .000 .

I can recommend that all investors should have equal opportunities and chances to participate at derivative profits. Hedging an investment position to reduce the risk is for about $11.85 \%$ of citizens in Germany directly or indirectly important [3]. All Investors are equally important for a market equilibrium and for efficient market prices, to for example establish arbitrage trades or force overbought asset prices, through short-sales, to decline and vice versa. The hedging and trading actions are not easy because knockouts can occur or sudden large losses (i.e., with Futures) can occur as part of the systemic market risk.

Therefore, this study can be relevant for lawmakers, financial advisors, retail traders, investors, banks, online brokers, or students to learn more about the impact and effect of $\mathrm{T}(2)$ on their investment profits. Further research could be conducted by other researchers in regard of the effects of taxation of other countries compared to the German taxation. For example, in South Korea short sales are forbidden, and in the United Kingdom (UK), or South African the taxation is given for the income derived by derivative contacts and transactions [21].

\section{REFERENCES}

1. The Wharton School \& The Chase Manhattan Bank, N. A. (1995). Survey of derivatives usage among U.S. non-financial firms. Philadelphia, PA.

2. Cummins, J. D., Phillips, R. D., \& Smith, S. D. (2001). Derivatives and corporate risk management: Participation and volume decisions in the insurance industry. Journal of Risk and Insurance, 51-91. https://doi.org/10.2307/2678132

3. Deutsches Aktieninstitut. (2021, February 3) Statistiken [Statistics]. https://dai.de/de/das-biteenwir/studien- und statistiken/statistiken.html?d=686

4. Derivateverband. (2021, February 1) Marktvolumen [market volume]. https://derivateverband.de/DEU/Statistiken/Markt vorlumen

5. Stout, L. A. (1998). Why the law hates speculators: Regulation and private ordering in the market for OTC derivatives. Duke LJ, 48, 701. https://heinonline.org/HOL/LandingPage?handle= hein.journals/duklr48\&div $=25 \&$ id $=\&$ page $=$

6. Deinwallner, U. R. (2019). Moving average: How do the ANDOR and ANDAND strategy perform in currency markets. International Research Journal of Applied Finance, 10(11), 299-314. Retrieved

from https://nebula.wsimg.com/32633e21ef617f878da1 f6e9d175e98a?AccessKeyId=A83663472B839EC DD54B\&disposition=0\&alloworigin $=1$

7. Finanztip. (2021, February 3). Kosten Wertpapierdopt bei Filialbank und Online Bank.[Cost of stock portfolio at branch bank and online broker]. https:/www.finanztip.de/wertpapierdepot/

8. Consorsbank. (2021, February 1). CFD Handel [CFD trading]. https://consorsbank.de/ev/wertpapierhandel/Depot -Software/CFD-Handel

9. Finanzkun. (2013). Sind Kursgewinne zu versteuern?[Are assetgains relevant fortaxation?]. https://finanzkun.de/artikel/sind-kursgewinne-zuversteuern/

10. Trading-Steuerberatung. (2021, February 3). Verlustverrrechnung für Aktine und Termingeschäfte ab 2021 - Alle Änderungen im Überblick [Loss offsettingforstocksand derivatives beginning 2021 - all changes in an overview] https://tradingsteuerberatung.de/verlustverrechnung-aktientermingeschaefte-ab-2021/ 
11. Ren, L., \& Ren, P. (2018). Applying a combined max-min simple moving average trading strategy to market indexes. Economics, Management, \& Financial Markets, 13(2), 1123.https://www.ceeol.com/search/articledetail?id=676861

12. Figlewski, S. (1984). Hedging performance and basis risk in stock index futures. The Journal of Finance, 39(3), 657669.https://doi.org/10.1111/j.15406261.1984.tb03654.x

13. Park, T. H., \& Switzer, L. N. (1995). Timevarying distributions and the optimal hedge ratios for stock index futures. Applied Financial Economics, 5(3), 131-137. https://doi.org/10.1080/758523000a

14. Deinwallner, U. R. (2020). Portfolio management: Hedge or sell during a crisis? Saudi Journal of Economics and Finance, 4(5), 162-169. https://doi.org/10.36348/sjef.2020.v04i05.001

15. Arnold, C. M., \& Rahfeldt, D. (1986). Timing the market: How to profit in bull and bear markets with technical analysis. Chicago, IL: Probus Publishing.

16. Chang, Y., Metghalchi, M., \& Chan, C. (2006). Technical trading strategies and cross-national information linkage: The case of Taiwan stock market. Applied Financial Economics, 16(10), 731-743. https://doi.org/10.1080/09603100500426374

17. Extra ETF. (2021, February 3). So funktionieren short ETFs [This is how short ETFs function]. https://de.extraetf.com/wissen/so-funktionierenshort-etfs

18. Finanzen.net. (2021, February 1). Hebelzertifikate - mit Hebelprodukten rednitestarkanlagen. [warrants - with leveraged assets gaining excess return].

https://www.finanzen.net/ratgeber/wertpapiere/heb elzertifikate

19. Abbey, B. S., \& Doukas, J. A. (2012). Is technical analysis profitable for individual currency traders? Journal of Portfolio Management, 39(1), 142-150. https://doi.org/10.3905/jpm.2012.39.1.142

20. Braun, A. (2020). Nachhaltig investieren simplified: Mehr Rendite mit ökologischer, ethischer und sozialer Geldanlage (1. Auflage). München: FinanzBuch Verlag.

21. Kruger, R. (2015). The taxation of financial derivative instruments in South Africa (Doctoral dissertation, University of Pretoria). http://hdl.handle.net/2263/50649 